\title{
ANÁLISE DE IMPACTO CAUSADO NO MEIO FíSICO PELO VAZADOURO DE RESÍdUOS SÓLIDOS DE LONDRINA E MEDIDAS MITIGADORAS PROPOSTAS
}

\author{
FERNANDO FERNANDES ${ }^{1}$ \\ SANDRA MÁRCIA CESÁRIO PEREIRA DA SILVA ${ }^{1}$ \\ CLEVERSON VITÓRIO ANDREOLI ${ }^{2}$ \\ ANDRÉ CELIGOI \\ GERALDO CÉSAR ROCHA ${ }^{3}$
}

\begin{abstract}
FERNANDES, F.; SILVA, S.M.C.P. da; ANDREOLI, C.V.; CELIGOI, A.; ROCHA, G.C. Análise de impacto causado no meio físico pelo vazadouro de resíduos sólidos de Londrina e medidas mitigadoras propostas. Semina:

Ci. Exatas/Tecnológicas, Londrina, v. 16, n. 4, p. 574-580, dez. 1995.

RESUMO: A área de 19,23 ha que recebia resíduos sólidos urbanos de Londrina foi submetida a levantamento topográfico, caracterização geológica e perfuração de poços para avaliação da qualidade das águas subterrâneas. Mesmo escolhida sem critério, a área pode receber resíduos sólidos urbanos desde que o plano mitigador seja implantado.
\end{abstract}

PALA VRAS-CHA VE: resíduos sólidos; impacto ambiental.

I. Introdução

O aterro sanitário de Londrina (PR) está situado na região sudeste da cidade, a aproximadamente $7 \mathrm{~km}$ do centro.

O local, escolhido sem nenhum critério técnico, começou a receber lixo em 1977 e tem 19,23 ha de área. A disposição dos resíduos foi feita empiricamente e sem nenhum preparo do local. Em 1993 o local recebia em média 224 ton/dia de lixo.

A falta de dados básicos sobre o local aliada à má ocupação do espaço gerou agressão ao meio ambiente e risco sanitário à população.

O objetivo deste trabalho foi avaliar o grau de impactação da área, principalmente com relação ao meio físico, analisar a viabilidade do local continuar a receber resíduos sólidos urbanos e propor medidas mitigadoras para adequar a área aos moldes de um aterro sanitário.

\section{Materiais e Métodos}

O trabalho foi iniciado com o levantamento planialtimétrico de toda a área em escala 1:1000 e 1:500.

Nas sondagens de solo e subsolo foram escavadas quatro trincheiras de $5 \mathrm{~m}$ de profundidade, um poço a céu aberto de 10 metros de profundidade, amostragens a trado e ensaios de penetração tipo SPT - Standart Penetration Test (CAPUTO, 1976).

As amostras coletadas nas sondagens a trado e SPT eram amolgadas. As coletadas no poço e trincheiras eram indeformadas.

Também foram escavados cinco poços de observação (piezômetros) para permitir a coleta e análise da água do subsolo.
Os levantamentos de campo seguiram o esquema simplificado de check list (MOREIRA, 1993) e se enquadram no critério proposto por Henriques (1994) para a avaliação de impactos em recursos hídricos (Anexo 1)

III. Resultados e discussão

A estrada de acesso fica no divisor de águas, sendo que o ponto mais alto do aterro fica anexo à estrada, declinando até o fundo do vale seco, com aclive suave em seguida. (Fig. 1)

A litologia aflorante é constituída pela formação Serra Geral, de idade Jurássico - Cretácea, composta por rochas basálticas.

Os solos da área são latossolos roxos profundos (oxisols), que se caracterizam pela estrutura granular e textura argilosa. A espessura média do solo, considerando-se os horizontes $A$ e $B$ é de $10 \mathrm{~m}$, sendo a cobertura homogênea ao longo da encosta. (Fig. 2)

A Figura 1 mostra os pontos de sondagem do subsolo (LX1 e LX5) e a locação dos poços de observação para coleta de águas subterrâneas.

O estudo geológico mostrou que as partes mais altas do terreno são áreas preferenciais de recarga do lençol freático (Fig. 2). Estas áreas contêm menor volume de lixo, e foi sugerida sua inativação, cobertura com terra e plantio de grama.

Uma escavação nesta área revelou a existência de uma vaia onde foi disposta, há vários anos, uma quantidade não definida de agrotóxicos.

O órgão ambiental (IAP) confirmou ter autorizado a disposição do produto. Este problema permanece em aberto e não foi tratado neste trabalho já que não havia

1 - Departamento de Construção Civil (CTU)- Universidade Estadual de Londrina, Telefone (043) 371-4455, Campus Universitário, Cx.

Postal 6001, CEP 86051-990 - Londrina - Paraná.

2 - Departamento de Solos - Universidade Federal do Paraná.

3 - Departamento de Geociências - Universidade Estadual de Londrina. 
dados quantitativos e qualitativos sobre os agrotóxicos enterrados.

O monitoramento das águas subterrâneas deve levar em conta este dado.

Os poços de observação (Fig. 3) mostraram que na área do aterro o lençol freático está a uma profundidade segura (8-10 m). A CETESB cita como referência uma distância mínima de 2,0 m entre a parte inferior do aterro e o lençol freático.

O solo apresentou coeficiente de permeabilidade média da ordem de $2,6 \times 10^{-6} \mathrm{~cm} / \mathrm{s}$, atingindo $10^{-7} \mathrm{~cm} / \mathrm{s}$ (praticamente impermeável) quando compactado. (Tabela 1)

O baixo coeficiente de permeabilidade, devido principalmente ao alto teor de argila (Fig. 4 e 5) permite a impermeabilização das superfícies das áreas a serem ocupadas utilizando-se o solo local com compactação controlada.

$\mathrm{Na}$ área havia uma vala construída sem qualquer critério técnico para reter o chorume produzido.

Foi então recomendada a construção de uma nova lagoa, totalmente impermeabilizada e desativação da antiga lagoa. (Fig. 1)

Os resultados das análises da água coletada nos poços de observação mostraram contaminação do lençol freático (Tabela 2), sendo provável que esta contaminação venha, em sua maior parte, por infiltração do chorume retido na antiga lagoa. A região de maior concentração de lixo (Fig. 1) também pode provocar infiltração de chorume.

Nos pontos de maior concentração de lixo, deve ser feita a remoção do maior volume possível deste material para uma área previamente compactada e dotada de drenos.

A compactação controlada e instalação de drenos de gás e chorume foi recomendada para toda a área a ser ocupada.

Devido à escassez de espaço recomendou-se a instalação de uma unidade de tratamento físico-quími- co para o chorume, em que o sulfato de alumínio é utilizado como floculador, seguido de decantação e filtração do efluente. O líquido tratado deve ser monitorado, passando, em seguida, por uma lagoa de polimento e poderá ser usado como água de irrigação para a área gramada ou viveiro.

A aproximadamente $800 \mathrm{~m}$ abaixo do aterro, seguindo o eixo do vale seco, estão as nascentes do córrego Piriquitos, afluente do rio Tibagi. Com base nos coeficientes de permeabiliade do solo, foi estimada a velocidade de deslocamento do fluxo subterrâneo como sendo da ordem de 160 metros por ano. Se tomarmos um período de ocupação da área de 15 anos, o poluente teria percorrido $2.400 \mathrm{~m}$. A nascente do córrego Piriquitos e os poços cacimba mais afastados certamente não captam os poluentes com tanta intensidade em virtude da nuvem poluente estar "afundando" em direção ao aqüífero Serra Geral.

Foram dimensionadas células em que o lixo deve ser compactado e recoberto diariamente com terra para evitar a proliferação de insetos vetores e limitar os odres.

0 monitoramento futuro, através dos poços de observação, avaliará quantitativamente a eficácia das medidas propostas. Este monitoramento deverá continuar ainda por vários anos após o encerramento do aterro.

\section{Conclusões}

1 - O local, embora escolhido sem critério técnico, apresenta condições aceitáveis para a disposição dos resíduos sólidos urbanos de Londrina, desde que sejam adotadas as medidas mitigadoras propostas.

2 - A contaminação do lençol freático observada, embora limitada, é preocupante devido à importância do aqüífero Serra Geral.

3 - As medidas de proteção recomendadas são usuais em aterros sanitários bem controlados, e o monitoramento da área deverá aferir sua eficácia.

\section{ANEXO 1 - Critério básico para avaliação da contaminação das águas subterrâneas (HENRIQUES, 1994)}

\begin{tabular}{|c|c|c|}
\hline CATEGORIA & SUB-CATEGORIA & INDICADOR AMBIENTAL \\
\hline \multirow[t]{8}{*}{ Geofísica } & Morfologia & * Relevo \\
\hline & & * Declives e orientaçäo do terreno \\
\hline & & * Bacias hidrográficas \\
\hline & & * Rede hidrográfica \\
\hline & Geologia & * Formaçōes geoiógicas \\
\hline & & ${ }^{*}$ Litologia \\
\hline & Solos & * Tipos de solo \\
\hline & & ${ }^{*}$ Características dos solos \\
\hline \multirow[t]{3}{*}{ Hidrologia } & Águas subterrâneas & * Caracteristicas dos aquiferos \\
\hline & & *Áreas de recarga \\
\hline & & *Vuinerabilidade à poluição \\
\hline Qualidade da & Águas subterrâneas & * Parâmetros físico-quimicos e mi \\
\hline
\end{tabular}


TABELA 1 - Resumo de algumas características do solo.

\begin{tabular}{|c|c|c|c|c|c|c|c|}
\hline \multirow[t]{3}{*}{$\mathbf{L X}$} & \multirow{2}{*}{\multicolumn{2}{|c|}{$\begin{array}{c}\text { Profundidade } \\
\text { (m) }\end{array}$}} & \multirow{2}{*}{\multicolumn{3}{|c|}{ Granulometria \% }} & \multicolumn{2}{|c|}{ Permeabilidade } \\
\hline & & & & & & natural & compactado \\
\hline & de & até & are & silte & argila & $(\mathrm{cm} / \mathrm{s})$ & $(\mathrm{cm} / \mathrm{s})$ \\
\hline & 1,00 & 1,22 & 8 & 17 & 75 & $5,1 \times 10^{-4}$ & \\
\hline & 2,50 & 2,80 & & & & $7,5 \times 10^{-5}$ & \\
\hline & 2,00 & 3,00 & & & & & $2,8 \times 10^{-7}$ \\
\hline 2 & 3,00 & 4,00 & 9 & 18 & 73 & & $4,2 \times 10^{-7}$ \\
\hline & 4,00 & 5,00 & & . & & , & \\
\hline & 5,00 & 6,00 & 9 & 8 & 84 & & \\
\hline & 7,00 & 8,00 & 10 & 8 & 82 & & \\
\hline & 1,00 & 1,30 & & & & & \\
\hline & 2,00 & 2,30 & 6 & 10 & 84 & & \\
\hline & 3,00 & 3,30 & & & & & \\
\hline & 4,00 & 4,30 & 7 & 10 & 83 & & \\
\hline & 5,00 & 5,30 & & & & & \\
\hline 3 & 6,00 & 6,30 & 7 & 7 & 86 & & \\
\hline & 7,00 & 7,30 & & & & & \\
\hline & 8,00 & 8,30 & 8 & 6 & 86 & & \\
\hline & 9,00 & 9,30 & & & & & \\
\hline & 10,00 & 10,30 & 10 & 11 & 79 & & \\
\hline & 11,00 & 11,30 & & & & & \\
\hline & 11,70 & 11,90 & 19 & 27 & 53 & & \\
\hline
\end{tabular}

TABELA 2 - Resultados das análises físico-químicas das prímeiras amostras de água coletadas nos poços de observação.

\begin{tabular}{lcccc}
\hline & P2 & P3 & P4 & P5 \\
\hline pH & 10,5 & 11,5 & 6,8 & 12,2 \\
Turbidez & 119 & 50 & 1720 & 112 \\
Sulfatos & 17 & 28 & 4 & 30 \\
Nitrogênio amoniaca\} & 0,46 & 0,29 & 0,41 & 0,55 \\
Nitrogennio orgânico & 0,65 & 0,67 & 11,88 & 0,62 \\
Fosfato total & 0,32 & 0,06 & 28,0 & 0,08 \\
DQO & 19 & 21 & 62 & 12 \\
DBO & 3 & 3 & 14 & 2 \\
\hline
\end{tabular}

Resultados em mg/l - (turbidez $\mathrm{NTU}$, sulfatos $\mathrm{SO}_{4}$, Nitrogênio $\mathrm{N}_{2}$ fosfato $\mathrm{P}, \mathrm{DBO}$ e DQO em mg/l de $\mathrm{O}_{2}$ ). 


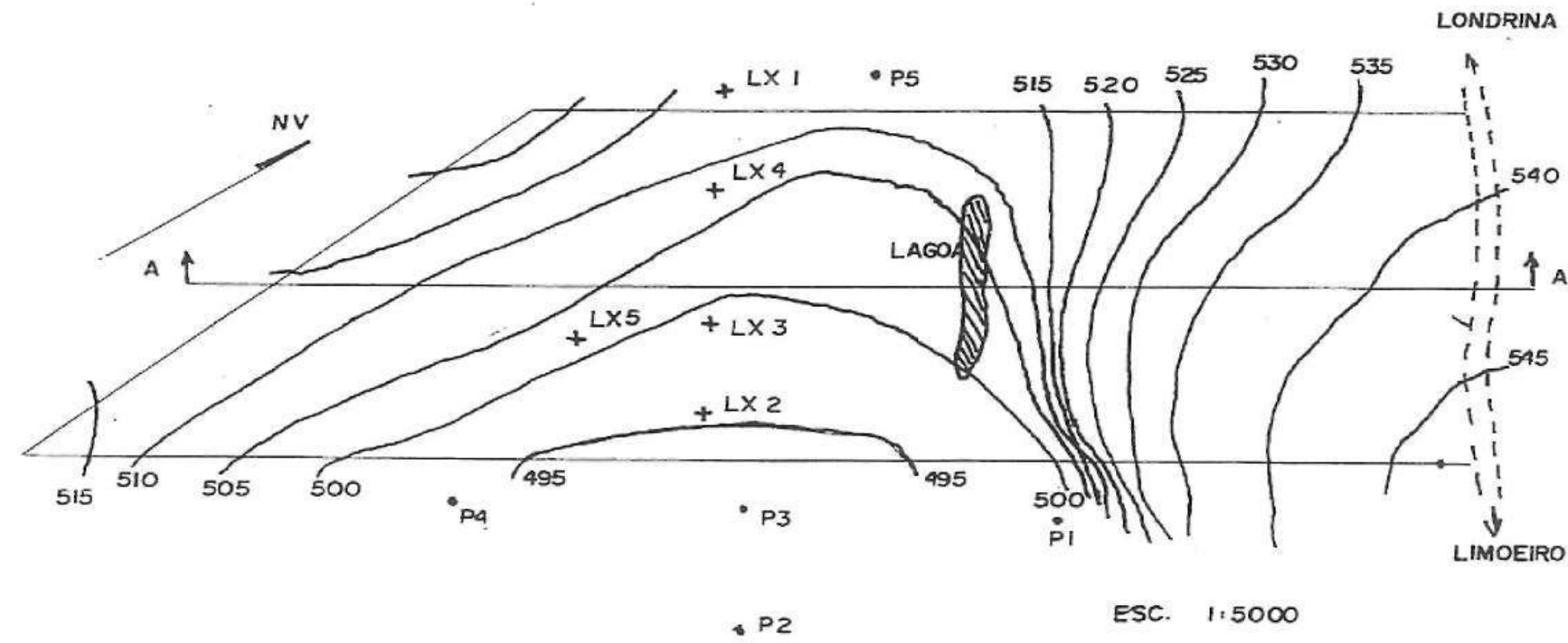

Indicuçāoo Topográfica e Pontos de Sondagem

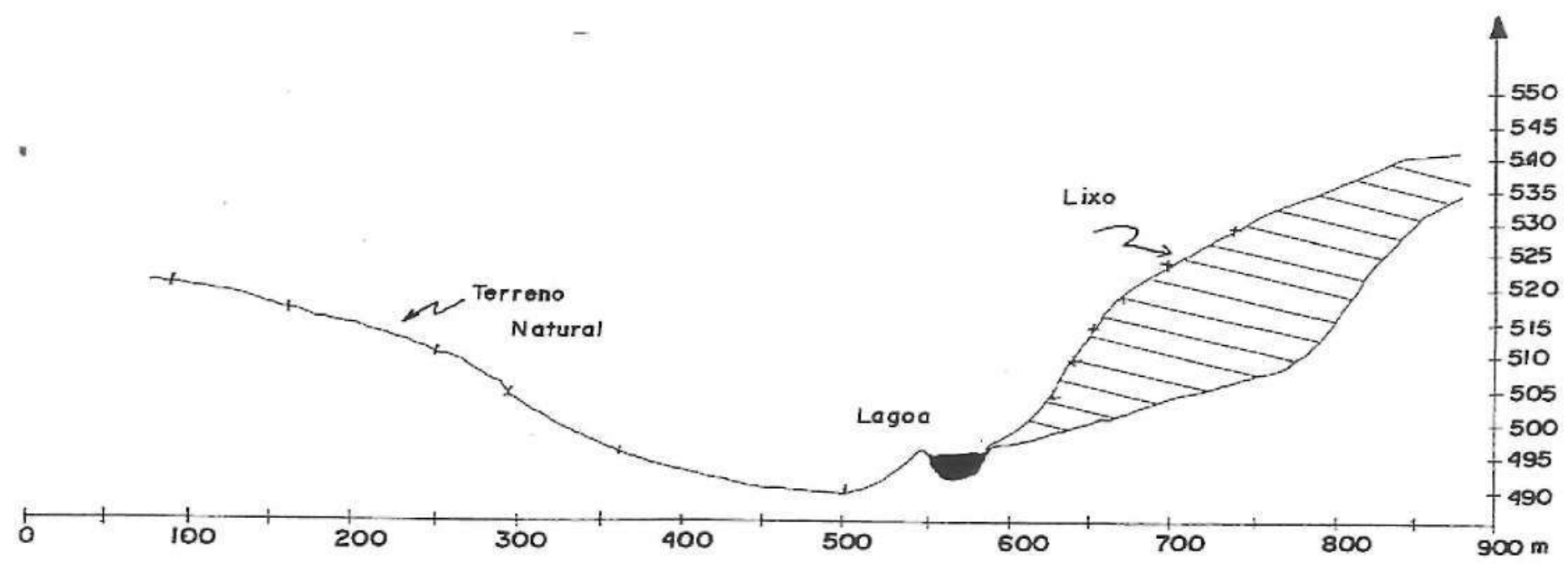

Perfil A-A

FIGURA 1 - Situação topográfica e locação dos pontos de sondagem 

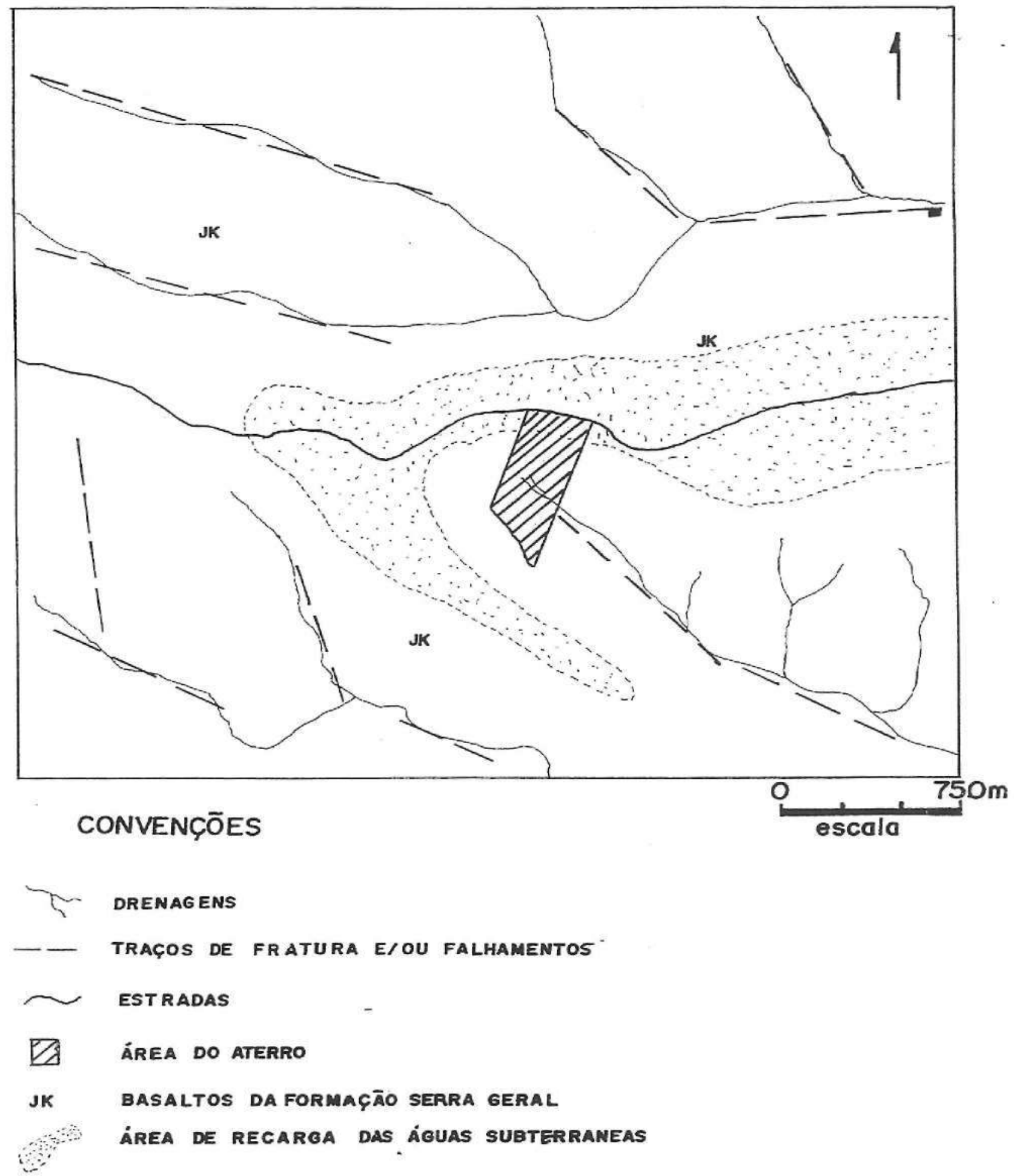

FIGURA 2 - Mapa geológico-estrutural do local e área de recarga de águas subterrâneas 


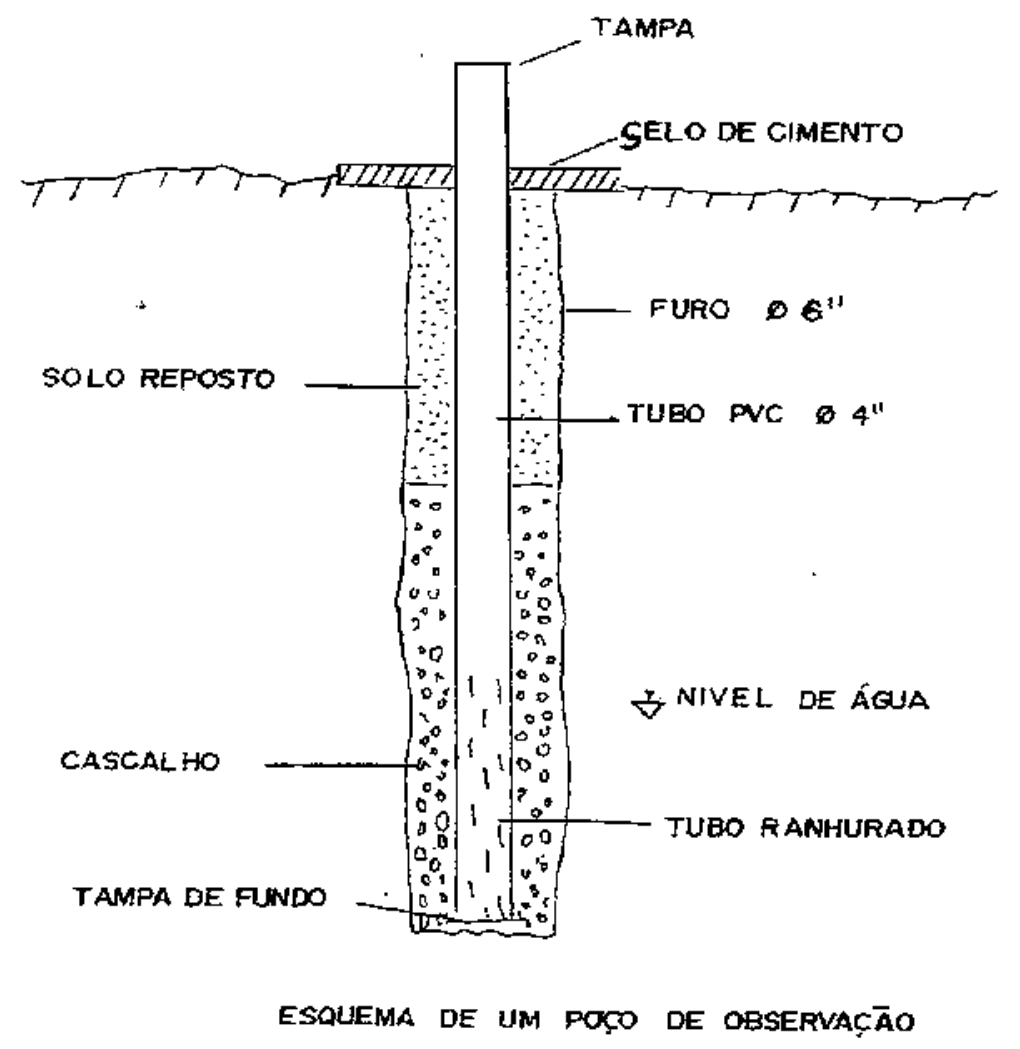

$\begin{array}{cc}\text { POSO } & \text { PROFUNDIDADE } \\ \text { PI } & 16.9 \mathrm{~m} \\ P .2 & 24,5 \mathrm{~m} \\ P 3 & 19.5 \mathrm{~m} \\ P 4 & 17,5 \mathrm{~m} \\ P 5 & 23,0 \mathrm{~m}\end{array}$

NIVEL ESTÁTICO

seco

$5,0 \mathrm{~m}$

$7,6 \mathrm{~m}$

$13,3 \mathrm{~m}$

$10,8 \mathrm{mp}$

FIGURA 3 - Características dos poços de observação e profundidades do lençol freático 


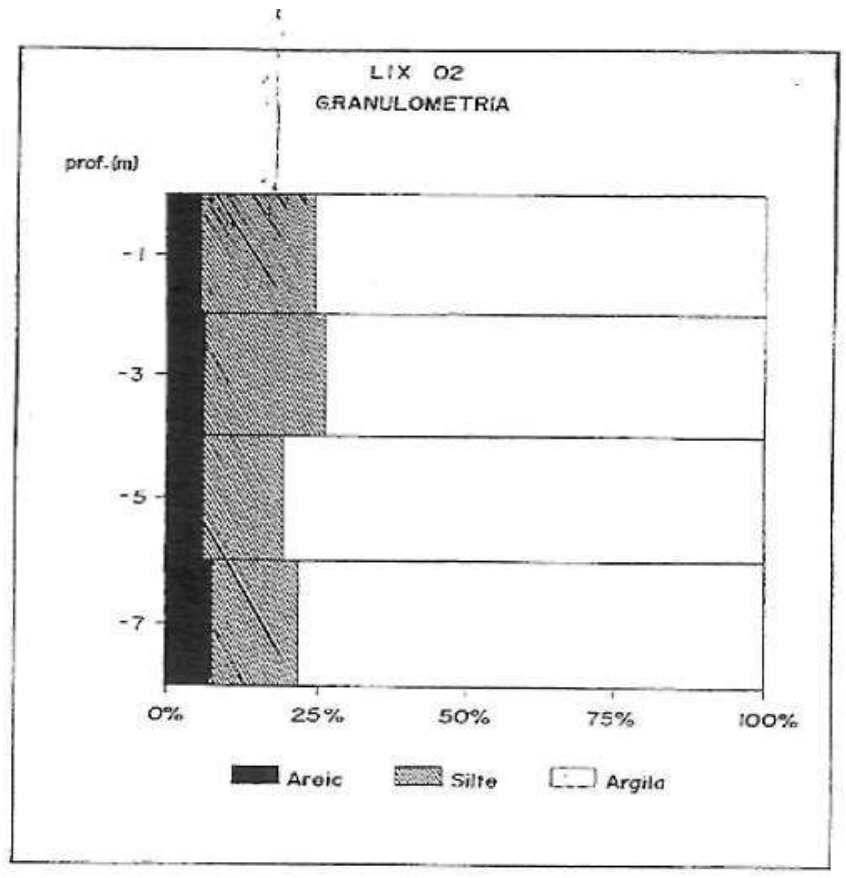

Figura 4 - Granulometria (LIX 02)

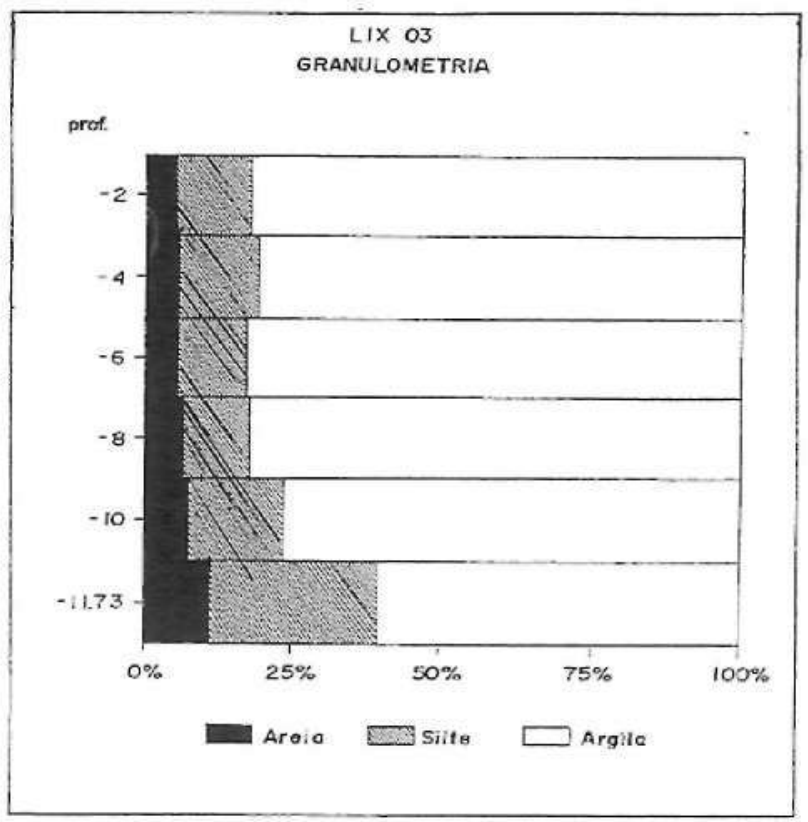

Figura 5 - Granulometria (LIX 03)

FERNANDES, F.; SILVA, S.M.C.P. da; ANDREOLI, C.V.; CELIGOI, A.; ROCHA, G.C. Analisys of the impact assessment caused by the municipal solid waste deposit of Londrina and mitigation plan proposed. Semína: Ci. Exatas/Tecnológicas, Londrina, v. 16, n. 4, p. 574-580, Dec. 1995.

ABSTRACT: A 19,23ha area used as a deposit of urban solid waste of Londrina was submitted to topographic survey, geological characterization and well drilling for quality evaluation of underground water. The area, although chosen without any criteria, is able to receive urban solid wastes if the mitigation plan proposed is irnplemented.

KEY-WORDS: solid waste; impact assessment.

\section{REFERÊNCIAS BIBLIOGRÁFICAS}

CAPUTO, H.P. Mecãnica dos solos. Ed. Livros Técnicos e Cientificos Ltcla, 1978.

HENRIQUES, A.G. Impacto ambiental nos recursos hidricos. In: "Avaliaçâo do impacto Ambiental". Centro de estudos de planeamento e gestão do ambiente (1994), Lisboa.

MOREIRA, I.V.D. Origem e sintese dos principais métodos e avaliaçāo de Impacto Ambiental. In: "Manual de Avaliação de Impactos Ambientais", 2 a. ediçāo (1993), Secretaria de Estado do Meio Ambiente. Curitiba. 